\title{
Expression of tissue polypeptide antigen (TPA) in fetal and adult liver: changes in liver disease
}

\author{
A D BURT, J A STEWART, M AITCHISON, R N M MACSWEEN \\ From the University Department of Pathology, Western Infirmary, Glasgow, Scotland
}

SUMMARY The distribution of tissue polypeptide antigen ( $40 \mathrm{kD}$ molecular weight) in normal adult and fetal liver, and in liver disease was investigated and compared with the distribution of low and high molecular weight cytokeratins. In normal liver tissue polypeptide antigen was found only in bile duct epithelium; this distribution is similar to that of high molecular weight cytokeratin, but differs from that of low molecular weight cytokeratins. In liver disease it was found in areas of ductular transformation; in Mallory's bodies; and in alcoholic liver disease and primary biliary cirrhosis in some hepatocytes that did not contain Mallory's bodies.

Tissue polypeptide antigen (TPA) is an unconjugated protein that is widely distributed in human epithelial tissues. ${ }^{1}$ It was first isolated from the water insoluble residue of carcinomas in the search for a common antigen associated with tumour. ${ }^{2}$ Antibodies raised against the major subunit, TPA B1, have been used in serological studies of patients with malignant tumours, and it has been suggested that increased serum concentration of TPA may indicate the presence of a malignant epithelial neoplasm. ${ }^{3-5}$ Increased concentrations of circulating TPA have, however, been detected in blood in several benign conditions. ${ }^{67}$ Lundstrom $\mathrm{et} \mathrm{al}^{7}$ showed that patients with acute hepatitis may have increased serum TPA concentrations but the tissue expression of this protein in liver disease has not been reported as far as we know.

The general tissue distribution of TPA suggests that it may be related to cytokeratins, ${ }^{2}$ the intermediate filament proteins of epithelial cells, ${ }^{18-10}$ but their precise biochemical relation is uncertain. The distribution of cytokeratins in human liver has been described in biochemical and immunohistochemical studies. ${ }^{11-17}$ In normal liver hepatocytes differ from bile duct epithelium in their cytokeratin profile, and certain liver diseases may be associated with abnormalities in hepatocytic cytokeratin metabolism. This study therefore aimed to investigate the distribution of TPA in normal adult and fetal liver, and in various liver diseases, and to compare this with the distribution of low molecular weight and high molecular weight cytokeratins.

\section{Material and methods}

\section{LIVER BIOPSY SPECIMENS}

Surgical wedge biopsy specimens and percutaneous needle biopsy specimens of liver were taken from the files of the University Department of Pathology, Western Infirmary, Glasgow. Tissue was available from patients with histologically normal liver taken at staging laparotomies $(n=8)$, congenital hepatic fibrosis $(n=3)$, fatty liver $(n=8)$, alcoholic hepatitis $(n=11)$, alcoholic cirrhosis $(n=15)$, extrahepatic biliary obstruction $(n=6)$, cholestasis induced by drugs $(n=4)$, autoimmune chronic active hepatitis $(n=7)$, primary biliary cirrhosis $(n=11)$, primary sclerosing cholangitis $(n=2)$, hepatocellular carcinoma $(n=4)$ and cholangiocarcinoma $(n=4)$. All biopsy specimens had been fixed in $10 \%$ buffered formol saline, post-fixed in formol sublimate, and processed to paraffin wax. Fetal liver tissue $(n=13$; gestation 15-28 weeks) was taken from specimens from spontaneous abortions sent to the Department of Pathology, Queen Mother's Hospital, Glasgow; this material was fixed in Bouin's fixative.

Five micron sections from each specimen were processed through graded alcohols and stained with haematoxylin and eosin, or mounted on slides coated with poly-L-lysine for the immunohistochemical studies.

\section{IMMUNOHIS TOCHEMISTRY}

Sections were treated with $0.1 \%$ trypsin (type II porcine T8128, Sigma Chemicals, England) in 0.1\% calcium chloride-phosphate buffered saline (PBS) for 10 minutes at $37^{\circ} \mathrm{C}$ before primary antibodies were 


\section{0}

applied. Anti-TPA B1 (rabbit polyclonal; concentration $200 \mu \mathrm{g} / \mathrm{ml}$ ) was supplied by CIS Ltd, England. Antikeratin (rabbit polyclonal; concentration $40 \mu \mathrm{g} / \mathrm{ml}$ ) was bought from Dako Ltd. This antibody was raised against human callus and recognises high molecular weight cytokeratins. CAM $5 \cdot 2$ antibody (mouse monoclonal; concentration $50 \mu \mathrm{g} / \mathrm{ml}$ ) was bought from Becton Dickinson Ltd; this antibody ${ }^{918}$ recognises an epitope on low molecular weight cytokeratins (Moll catalogue 8, 18, and 19).

The peroxidase-antiperoxidase (PAP) technique was used on sections treated with anti-TPA and antikeratin, ${ }^{19}$ and the avidin-biotin peroxidase method was used on sections treated with CAM 5.2. ${ }^{20}$ Peroxidase labelling in slides treated with PAP and with avidin-biotin was shown using the method of Graham and Karnovsky. ${ }^{21}$ Sections were subsequently counterstained with haematoxylin and read under a Leitz III microscope; Nomarski filters and phase contrast were used to accentuate contrast.

\section{Results}

DISTRIBUTION OF TPA AND CYTOKERATINS IN NORMAL ADULT AND FETAL LIVER

In normal adult liver staining with anti-TPA antibody was confined to bile duct epithelium, where it was seen throughout the cytoplasm (fig 1); bile duct radicles of all calibres showed similar appearances. Staining with antikeratin was also limited to bile duct epi-

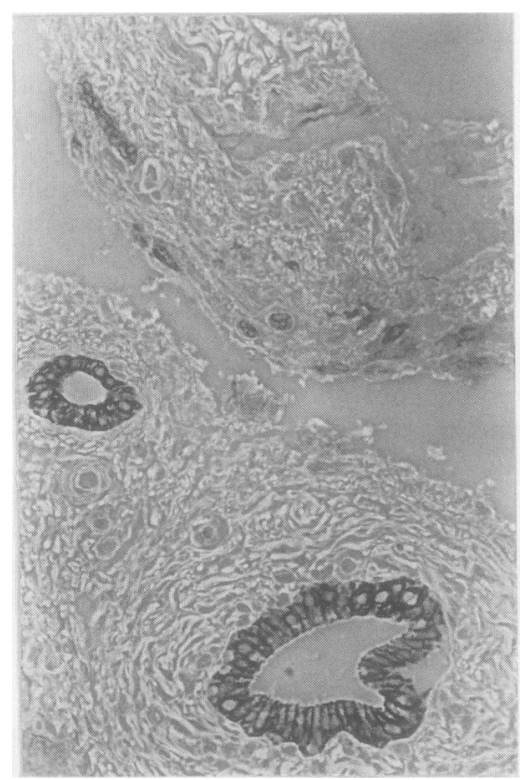

Fig 1 TPA immunoreactivity in normal bile duct epithelium (phase contrast).
Burt, Stewart, Aitchison, MacSween

thelial cells, and the intracellular distribution was similar to that of TPA. Using the methods outlined above, staining was more intense with anti-TPA than with antikeratin. The intensity of staining with both antibodies was enhanced by adding trypsin; in some sections reactivity to keratin could not be seen if this was not done. CAM 5.2 antibody stained the bile duct epithelial cells but also stained some hepatocytes (fig 2). There was variation in the distribution of CAM 5.2 immunoreactive hepatocytes within hepatic acini although no consistent topographical distribution could be identified. Sinusoidal cells were consistently negative with all antibodies.

The distribution of TPA, keratin, and CAM $5 \cdot 2$ immunoreactivity in fetal liver was similar to that seen in adult liver. In specimens taken from fetuses less than 20 weeks old, a layer one cell thick of cells positive for TPA was commonly found at the junction between parenchyma and mesoderm; in some areas this monolayer had duplicated, which corresponded to the development of primitive ductular structures (fig 3); this was also seen in the livers of two fetuses 24 weeks old, but in these the monolayers were more often seen in small portal tracts.

\section{DISTRIBUTION OF TPA AND CYTOKERATINS IN LIVER DISEASE}

The profile of TPA and cytokeratin distribution in hamartomatous bile ducts in cases of congenital hepatic fibrosis was identical with that seen in normal

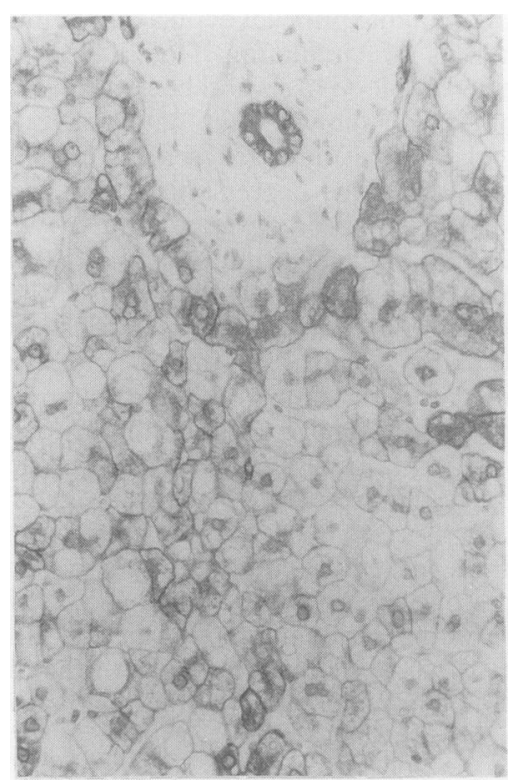

Fig 2 CAM $5 \cdot 2$ immunoreactivity in normal liver: positive staining is seen in bile duct epithelium and some hepatocytes. 


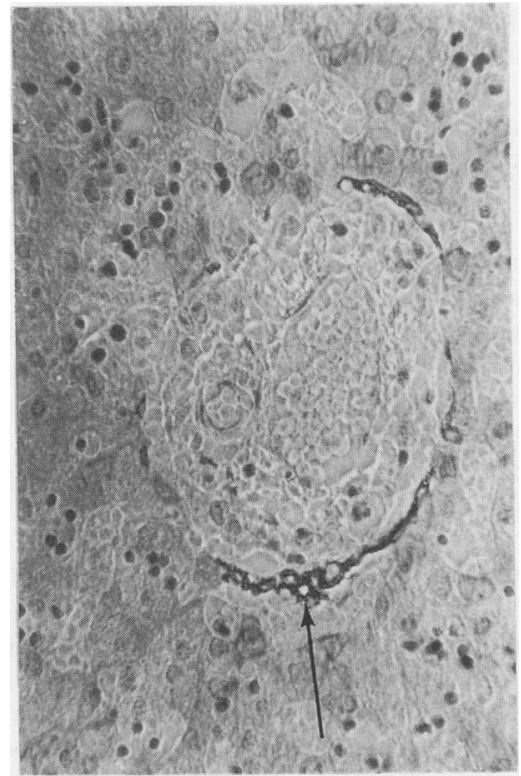

Fig 3 Positive staining for TPA in single layer of cells at parenchymal mesodermal junction in fetal liver at 18 weeks' gestation. Pattern of duplication is seen in developing ductal structures (arrow).

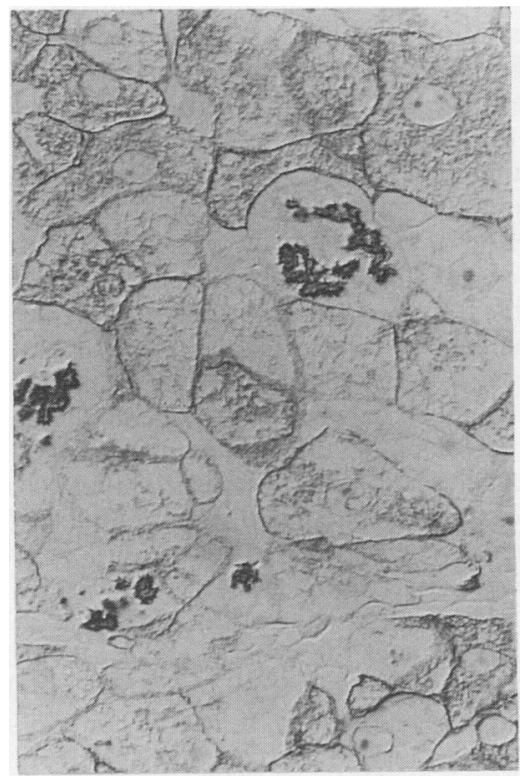

Fig 5 Strong staining for TPA in Mallory's bodies in primary biliary cirrhosis.

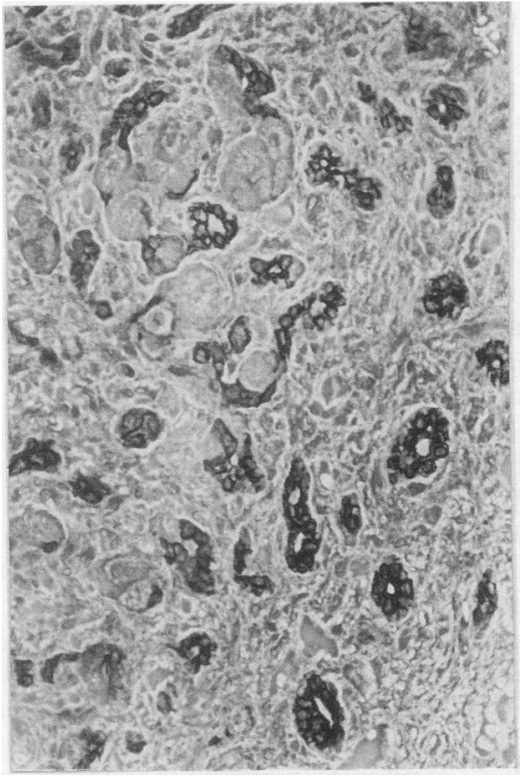

Fig 4 TPA immunoreactivity in area of proliferating bile ducts in primary biliary cirrhosis.

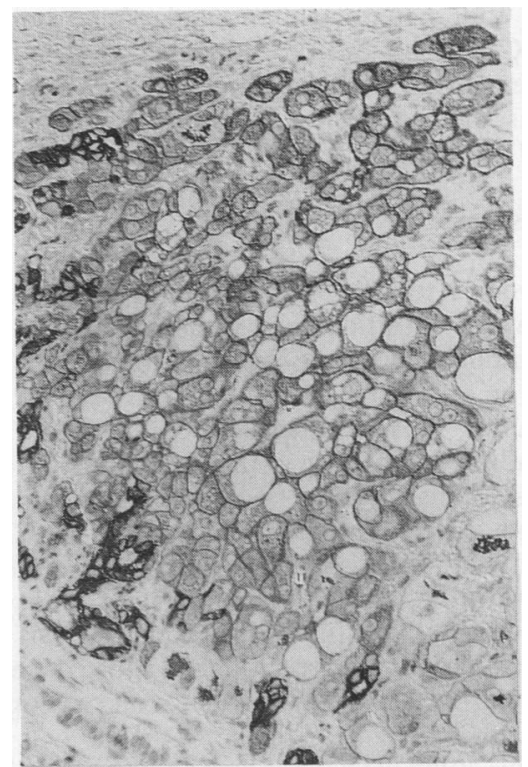

Fig 6 TPA distribution in alcoholic cirrhosis. Note intense staining of proliferating bile ductules and diffuse cytoplasmic staining in most hepatocytes within cirrhotic nodule. 
bile duct epithelium. Proliferating bile ductules in all cases of biliary tract disease were strongly positive with anti-TPA and CAM 5.2 and were weakly positive with antikeratin (fig 4). A similar profile was seen in areas showing apparent ductular transformation of hepatocytes in four of seven cases of chronic active hepatitis.

In nine of 11 cases of alcoholic hepatitis, seven of 15 cases of alcoholic cirrhosis, and four of 11 cases of primary biliary cirrhosis Mallory's bodies were strongly positive with anti-TPA (fig 5) and CAM $5 \cdot 2$ and weakly positive with antikeratin. The cytoplasm of cells containing Mallory's bodies was otherwise negative; a central negative core was also often seen within them. Anti-TPA and CAM 5.2 antibodies enabled us to see Mallory's bodies in some cases in which they were not visible in conventionally stained sections.

In some biopsy specimens hepatocytes that did not contain Mallory's bodies exhibited cytoplasmic TPA positivity. This appearance was usually seen in zone III of the acinus in cases of alcoholic hepatitis, at the periphery of nodules in alcoholic cirrhosis, and in acinar zone $I$ in primary biliary cirrhosis. In some cases the change was diffuse, apparently occurring throughout surviving acini and cirrhotic nodules (fig 6). A few TPA positive hepatocytes were also positive with the antikeratin antibody. Weak cytoplasmic staining for TPA was also noted in zone III hepatocytes in two cases of fatty liver; no Mallory's bodies were seen in these two biopsy specimens.

All four hepatocellular carcinomas were positive with CAM 5.2, but did not react with anti-TPA or antikeratin. In contrast, three of four cholangiocarcinomas showed positive staining with anti-TPA and CAM $5 \cdot 2$ and weak focal staining with antikeratin.

\section{Discussion}

Antibodies to TPA have been used to measure its serum concentrations as a tumour marker, ${ }^{3-5}$ and in immunohistochemical investigations of its distribution in breast tumours and salivary gland tumours. ${ }^{22} 23$ The general distribution of TPA and the finding of a fibrillary staining pattern in some cells suggested that it may be associated with the intermediate filament system of epithelial cells. ${ }^{1}$ The main subunit, TPA B1, is a single chain polypeptide weighing $40 \mathrm{kD}$ that is soluble in $10 \mathrm{M}$ urea, and which has an isoelectric focusing point of $\mathrm{pH} 4 \cdot 5 .^{24}$ These biochemical properties are similar to those of certain low molecular weight cytokeratins (Moll catalogue 8, 18, and 19).

In this study we have shown that the distribution of TPA in the liver differs from that of low molecular weight cytokeratins and more closely resembles that of higher molecular weight cytokeratins. The differences between the distribution of CAM 5.2 and keratin immunoreactivity in the liver confirm the findings of studies which have shown that normal hepatocytes contain only low molecular weight cytokeratins (52 kD "component A" and $45 \mathrm{kD}$ "component D"), while bile duct epithelium also contains higher molecular weight cytokeratins. ${ }^{11} 1314$ The pattern of staining in hepatocellular and cholangiocarcinomas resembled that of their cells of origin; staining with anti-TPA and antikeratin antibodies may help differentiate betwen these tumours and in cases of possible mixed differentiation.

In fetal liver developing bile ducts were also strongly positive for TPA. In specimens from fetuses less than 20 weeks old a layer of cells positive for TPA was often seen round portal tracts; these cells were small and cuboidal, when compared with the adjacent parenchymal cells. In some sections ductular structures had developed by a process of reduplication from these monolayers. These cells corresponded to the bile duct precursor cells previously described, and may be derived from parenchymal cells that have been transformed by the inductive effect of adjacent mesoderm. ${ }^{25}$ This process begins at seven weeks' gestation; by 16 weeks the biliary system is functionally competent. The results of our study suggest that the induction effect expression of TPA by these cells. Furthermore, although these are most abundant in fetuses of less than 20 weeks' gestation, such cells could be recognised immunohistochemically as late as 24 weeks, implying that the intrahepatic biliary system continues to develop after bile has started to flow.

Proliferating bile ducts in all cases of biliary disease showed the TPA-cytokeratin profile of normal bile duct epithelium. The so called proliferating ductules seen in biliary tract disease may result from both true proliferation of existing ducts and also from ductular metaplasia of hepatocytes. ${ }^{2627}$ The mechanism responsible for this metaplastic change may be similar to the change that occurs in fetal liver, the induction effect in the adult being mediated by changes in the adjacent extracellular matrix and mesenchymal cells.

Abnormal hepatocytic TPA expression was found in alcoholic liver disease and primary biliary cirrhosis, both diseases associated with the presence of Mallory's bodies. The precise nature of Mallory's bodies is controversial ${ }^{28}$; ultrastructurally they show some resemblance to intermediate filaments, ${ }^{29} 30$ although their mean diameter is greater. One and two dimensional SDS PAGE electrophoresis of solubilised Mallory's bodies has shown that they contain several polypeptides, two of which have electrophoretic features similar to those of the low molecular weight cytokeratins (components A and D) of normal hepatocytes. ${ }^{1631}$ Further evidence of their hetero- 
geneous nature has been shown in immunofluorescence studies. Denk et al showed that they react with antibodies to high molecular weight cytokeratins (prekeratin), ${ }^{32}$ and to components $\mathbf{A}$ and D. ${ }^{16}$ Morton et al have shown that they may also contain unique non-cytokeratin antigenic determinants detected by a polyclonal anti-MB antibody and a monoclonal antibody, JMB1.33 34 The immunohistochemical results presented here support such antigenic heterogeneity, and suggest that Mallory's bodies are composed of an accumulation of low molecular cytokeratins-normal constituents of hepatocytes-and higher molecular weight cytokeratins and TPA, which are normally restricted to bile duct epithelium.

Aberrant expression of TPA was also seen in some hepatocytes in cases of alcoholic hepatitis, cirrhosis, and primary biliary cirrhosis. These hepatocytes did not contain Mallory's bodies, and showed a diffuse cytoplasmic staining with some accentuation at the cell membranes. This may represent abnormal accumulation of TPA at a stage before the development of Mallory's bodies. Ray $^{35}$ showed abnormal distribution of high molecular weight cytokeratins in hepatocytes in alcoholic liver disease, with a similar distribution and incidence to that which we describe for TPA, using a combination of two monoclonal antibodies, AE1 and AE3. In the present study high molecular weight cytokeratin (keratin) positivity was also seen in some cases, although the intensity of staining was less than that seen with anti-TPA. This may in part reflect differences in affinity of these different antibodies on fixed tissue. Interestingly $\mathrm{Ray}^{35}$ found abnormal distribution of cytokeratin in cases of uncomplicated fatty liver similar to that of TPA in the two cases in our study. The clinical importance of this is uncertain, but it may represent an early phenotypic manifestation of chronic liver injury that will lead to the formation of Mallory's bodies.

We thank CIS Ltd for supplying the anti-TPA antibody. The study was partially funded by grants from the Scottish Home and Health Department, and the Research Fund of the University of Glasgow. We are grateful to Drs AAM Gibson and A Patrick for supplying the fetal material.

\section{References}

I Nathrath WBJ, Hedenkummer P, Bjorklund V, Bjorklund B. Distribution of tissue polypeptide antigen (TPA) in normal human tissues. J Histochem Cytochem 1985;33:99-109.

2 Bjorklund B, Lundblad G, Bjorklund V. Antigenicity of pooled human malignant and normal tissues by cytoimmunological technique II. Nature of tumor antigen. Int Arch Allergy Appl Immunol 1958;12:241-9.
3 Mendenez-Botet CJ, Oettgen HF, Pinsky CM, Schwartz MK. A preliminary evaluation of tissue polypeptide antigen in serum or urine (or both) of patients with cancer or benign neoplasms. Clin Chem 1978;24:868-73.

4 Panucci A, Fabris C, Favero G, et al. Is tissue polypeptide antigen more accurate than serum CEA for diagnosing pancreatic cancer? J Clin Pathol 1986;39:75-7.

5 Nemita T, Constantine R, Chu MT. Human tissue polypeptide antigen in breast cancer. $J N C I$ 1979;63:1347-52.

6 Holyoke D, Chu TM. Tissue polypeptide antigen. In: Herberman RB, McIntyre KR, eds. Immunodiagnosis of cancer. New York: Marcel Dekker, 1979:513-21.

7 Lundstrom R, Bjorklund B, Eklund G. A tissue derived polypeptide antigen: its relation to cancer and its temporary occurrence in certain infectious diseases. In: Bjorklund B, ed. Immunological techniques for detection of cancer. Stockholm: Bonniers, 1973:243-7.

8 Cooper D, Schermer A, Sun TT. Classification of human epithelia and their neoplasms using monoclonal antibodies to keratins: strategies, applications and limitations. Lab Invest 1985;52:243-56.

9 Moll R, Franke WW, Schiller DL, Geiger B, Krepler R. The catalogue of human cytokeratins. Cell 1982;31:11-24.

10 Lazarides E. Intermediate filaments: a chemically heterogeneous developmentally regulated class of proteins. Annu Rev Biochem 1982;51:219-50.

11 Franke WW, Denk H, Kalt R, Schmid E. Biochemical and immunological indentification of cytokeratin proteins present in hepatocytes of mammalian liver tissue. Exp Cell Res 1981;131:299-318.

12 Sun TT, Shih C, Green H. Keratin cytoskeletons in epithelial cells of internal organs. Proc Natl Acad Sci USA 1979;76:2813-6.

13 Schlegel R, Banks-Schlegel S, Pinkus GS. Immunohistochemical localisation of keratin in normal human tissues. Lab Invest 1980;42:91-9.

14 Denk H, Krepler R, Lackinger E, Artlieb U, Franke WW. Biochemical and immunocytochemical analysis of the intermediate filament cytoskeleton in hepatocellular carcinomas and in hepatic neoplastic nodules of mice. Lab Invest 1982;46: 584-96.

15 Denk H, Lackinger E. Alcoholic heptatitis: a disease of the cytoskeleton. In: Brunner H, Thaler H, eds. Hepatology: a festschrift for Hans Popper. New York: Raven Press, 1985:47-50.

16 Denk H, Franke WW, Dragosics B, Zeiler I. Pathology of cytoskeleton of liver cells: demonstration of Mallory bodies (alcoholic hyalin) in murine and human hepatocytes by immunofluorescence microscopy using antibodies to cytokeratin polypeptides from hepatocytes. Hepatology 1981;1: 9-20.

17 Fleming K, MacGee JO'D. Pathology of alcohol-induced liver disease. J Clin Pathol 1984;37:721-33.

18 Makin CA, Bobrow LG, Bodmer WF. Monoclonal antibody to cytokeratin for use in routine histopathology. J Clin Pathol 1984;37:975-83.

19 Sternberger LA, Cucullis JS. Method of enzymatic identification of immunocytochemical reaction without use of labelled antibodies. J Histochem Cytochem 1969;17:190-3.

20 Hsu M, Raine L, Fauger M. Use of avidin-biotin peroxidase complex (ABC) in immunoperoxidase techniques. $J$ Histochem Cytochem 1981;29:577-80.

21 Graham RC, Karnovsky MF. The early stages of absorption of injected horse radish peroxidase in the proximal tubule of mouse kidney: ultrastructural cytochemistry by a new technique. J Histochem Cytochem 1966;14:291-9.

22 Bjorklund V, Bjorklund B, Wittekind C, Von Kleist S. Immunohistochemical localisation of tissue polypeptide antigen (TPA) and carcinoembryonic antigen (CEA) in breast cancer. Acta Pathol Microbiol Immunol [A] 1982;90:471-6.

23 Caselitz J, Seifert G, Bjorklund B, Bjorklund V. Detection of tissue polypeptide antigen in salivary glands and salivary gland 
tumours: an immunohistochemical study. Appl Pathol 1983;1:115-20.

24 Luning B, Wiklund B, Redelius P, Bjorklund B. Biochemical properties of tissue polypeptide antigen (TPA). Biochem Biophys Acta 1980;624:90-6.

25 Hamilton WJ, Mossman HW. Human embryology: prenatal development of form and function. Cambridge: Heffer \& Sons, 1972:339-49.

26 Desmet VJ. Intrahepatic bile ducts under the lens. $J$ Hepatol 1985;1:545-59.

27 International Group. Histopathology of the intrahepatic biliary tree. Liver 1983;3:161-75.

28 French SW. The Mallory body: structure, composition, and pathogenesis. Hepatology 1981;1:76-83.

29 Yokoo H, Munick OT, Bath F, Kent G. Morphologic variants of alcoholic hyalin. Am J Pathol 1972;69:25-40.

30 Wiggers KD, French SW, French BA, Carr BN. The ultrastructure of Mallory body filaments. Lab Invest 1973;29:652-8.

31 Tinberg HM, Regan RJ, Geier EA, Peterson GE, French SW. Mallory bodies. Isolation of hepatocellular hyalin and electrophoretic resolution of polypeptide components. Lab Invest
1978;39:483-90.

32 Denk H, Franke WW, Eckerstorfer R, Schmid E, Kerjaschki D. Formation and involution of Mallory bodies ("alcoholic hya lin") in murine and human liver revealed by immunofluorescence microscopy with antibodies to prekeratin. Proc Natl Acad Sci USA 1979;76:4112-6.

33 Morton JA, Fleming KA, Trowell JM, McGee JO'D. Mallory bodies-immunohistochemical detection by antisera to unique non-prekeratin components. Gut 1980;21:727-33.

34 Morton JA, Bastin J, Fleming KA, McMichael A, Burns J, McGee JO'D. Mallory bodies in alcoholic liver disease: identification of cytoplasmic/cell membrane determinants by monoclonal antibodies. Gut 1981;22:1-7.

35 Ray MB. Distribution patterns of cytokeratin antigen determinants in alcoholic and non-alcoholic liver disease. Human Pathol 1987;18:61-6.

Requests for reprints to: $\mathrm{Dr}$ AD Burt, University Department of Pathology, Western Infirmary, Glasgow G11 6NT, Scotland. 